\title{
Analysis of occupational demand for patent agents in China - Based on the network data of recruitment
}

\author{
Li Gu*, Yiying Zhou, Liqiang Ren, Weichun Yan \\ Department of Public Administration, School of Public Administration and Law, Dalian University of Technology, Dalian 116024, P.R. China
}

\begin{abstract}
A statistical analysis technique is proposed to research and analyze the quality of patent agents. We apply time nodes and collect data and try to explore the demand for "patent agents" for China's intellectual property rights of enterprises and the quality requirements of patent agents. The study found that the enterprise demand for patent agents will continue to increase, but the academic requirements for applicants to the enterprises are not very high, the enterprises prefer the patent agents to have professional work experience. In addition, the majors of patent agents are strictly limited and targeted: Languages, majors, and professional experience constitute the basic configuration of patent agent quality.
\end{abstract}

Keywords: Demand, network recruitment, patent agent, quality

\section{INTRODUCTION}

The patent, which is "tangible evidence" of technological innovation and invention, is considered an effective method of protecting inventors' technological innovation, as well as an important indicator for measuring the country's level of development of science and technology. Currently, many countries, especially developed countries, have strengthened the protection and use of patent property which is a strategy to win and maintain international competitiveness in the fields of science and technology and economic development, etc. In China, to further improve the competitiveness of national science and technology, the government has made the development strategy of constructing an innovation country central, an important part of which is enhancing the patent property.

\section{*Address for correspondence:}

E-mail: guli@dlut.edu.cn

\begin{tabular}{|l|l|}
\hline \multicolumn{2}{|c|}{ Access this article online } \\
\hline Quick Response Code: & Website: \\
\hline & www.jscires.org \\
& Dol: \\
& $10.4103 / 2320-0057.167253$ \\
\hline
\end{tabular}

China's economy and technology have experienced astounding growth in the last 2 decades. ${ }^{[1]}$ Especially in recent years, China's patent applications and authorization rapidly increased in number, from more than 800,000 and 400,000 in 2008, respectively, to 1633,000 and 961,000 in 2012. In addition, the top 5 applicants for patents and invention were in electrical motors; electrical device; electric power, measuring, computer technology, mechanical engineering, and civil engineering, which further suggests that China's patent invention in technical field has begun to boom along with its fast economic growth. Patents have good commercial value, and China's huge patent information is critical and important for reflecting differences in technology capacity, ${ }^{[2-4]}$ so the role of patent in society, the economy and life is becoming increasingly highlighted. As a result, the social demands for patent agents have continued to grow. Network recruitment, a popular employment pattern, ${ }^{[5]}$ plays a significant role in hiring patent agents and the information can, accurately and in detail reflect all aspects of the requirements of the talent market for patent agents. High-quality patent agents have a vital role for improving the quality of patents. They can completely describe the invention that a principal designed and effectively help the principal avoid various modifications and alternatives that other competitors might think of so that better protection for the patent and the invention is realized. In China, patent agents come mainly 
from education, professional qualification examinations, and practitioners who have worked experience. However, the growth rates of patent agent qualifications and patent agent performers are $42 \%$ and $55 \%$, respectively, obviously trailing the growth rate of patents which is $257 \%$. The serious shortage of patent agents in quantity is not only unable to meet the market demands, but cannot reflect the requirement of the state for the quality of patent applications.

Therefore, the objective of this study was to perform a scientometric analysis of the competency of patent agents based on statistics collected through network recruitment. The central questions are:

- Analyzing the present situation of patent agents in China;

- Exploring the current market demand for patent agents and concrete connotation in China;

- Providing the suggestions to personnel training and the education of Chinese patent agency services.

\section{LITERATURE REVIEW}

A patent agent is an agent who has the specialized qualifications necessary for representing clients in obtaining patents and acting in all matters and procedures relating to patent law and practice. ${ }^{[6]}$ The term patent agent is employed differently in different countries, so the understanding of patent agent is diverse.

Cropp $^{[7]}$ found that a patent agent's duty is to guide the layman through the intricacies of patenting. Patent agents are divided into two types: Those in private practice and those in industrial (or tied) practice. Patent agents in private practice must rely very heavily on experts for information on the state of the art, and the historical background in any particular area. The tied patent agent, however, is generally in a relatively small area of technology, and his general reliance on the information retrieval expert is that much reduced. Lamoreaux et al. ${ }^{[8]}$ thought that in addition to helping an inventor draft and file patent applications, patent agents, and patent attorneys also often advise the firm on the merits of new technologies in the firm's industry. Yun ${ }^{[0]}$ thought that the legislative definition of patent attorney in South Korea reflects the professionalism offered by the patent attorney, therefore, the general job description includes illustrative examples of tasks conducted by specialists who protect the rights in invention, design, and trademark. Overall, the scope of the patent attorney's work is defined by a general descriptive language, which leaves ambiguity in interpreting the boundary, and the limitations in the tasks that a patent attorney may handle in the Korean legal system. Bottomley ${ }^{[10]}$ thought that the patent agent could represent the patent applicant in some legal proceedings, reducing the amount of time that the applicant had to spend in London. In addition, the patent agents, through their connections with entrepreneurs, manufacturers, and capitalists, could help the inventor find funding, both to pay patent fees and to eventually bring the invention to market. In China, the patent agent is defined as a professional who has obtained patent agent qualification, and was employed in a career agency. He belongs to the agent of the civil legal relationship but is also different from a general agent. ${ }^{[1]}$

Therefore, the requirement of patent agent competencies is diverse because of the different understanding of patent agent. Some scholars put forward the following views. Macdonald and Lefang ${ }^{[12]}$ examined the advantages of what might become an alternative indicator of innovation - the activities of the patent attorney, they found that the qualifications, skills and experience of the patent attorney are in the law and, in particular, the law relating to intellectual property, and that patents would grant patent attorneys a privileged position in the provision of these services. Thacker ${ }^{[13]}$ thought that almost all patent agents have a science or technology degree and quality in all aspects of the law relating to intellectual property by taking professional examinations. Based on an empirical study, Ralph and Thomas ${ }^{[14]}$ demonstrated that patent attorneys and agents should have relevant experience in the most often patented areas today, such as computer science. Gaff ${ }^{[15]}$ thought that at the higher end are searches performed by patent attorneys, and the patent attorney might follow-up with the search firm to perform refined searches based on the initial results. More importantly, however, the patent attorney should carefully analyze the claims in the patents, utilizing proper legal methods to determine what they cover. In addition, patent agents should also know the basics of patent law well and establish a close working relationship with the inventor, ${ }^{[16,17]}$ so that they can play an important role in the broadest possible patent protection.

Based on the above scholars' point of view, we can see that although they have different opinions to the patent agent and their quality requirement they have not reached a consensus. However, they all tend to the recognition that the patent agent is an emerging interdisciplinary professional, characterized by legality, professionalism. 


\section{DATA AND METHODS}

In this paper, we chose a network recruitment website - 51 jobs - as a data source. The website is the first professional human resources service that combines a variety of advantages of media resources in China, and it has repeatedly been rated as "China's most influential recruitment website" due to its having the largest position information database. Then, we set a time node (2014-4-4, at 13:12), and we search "patent agent" for retrieval in "position" search items in the 51 job web, the retrieval results display in total 46 pages with 1360 records. After eliminating duplicate and invalid information (including patent agent assistant, senior patent attorney, and consultant), we eventually obtain 276 valid records. Each of the parameters in the recruitment information (position name, enterprise name, place of work, enterprise scale, degree, demand, work experience, professional, special requirements, and language requirements) as an indicator is input into Excel form, building up a "patent agent quality requirement information database." After screening, calculating and counting the index in the database, we obtain the basic information of the patent agent quality data [Table 1]. Then, after statistical analysis of the data, we do further research on the competencies of patent agents from four aspects: Location, the scale of the enterprise, analysis of demand, and the quality of personnel requirements.

\section{RESULTS}

We obtained 276 recruitment records released by 243 units throughout the country, with the enterprise scale also being different.

\section{Location}

In China, patents are highly clustered into two groups of provinces: One is the economically fast growing coastal provinces; and the other is inland provinces with large population bases while the degree of spatial concentration of patents is declining over time. ${ }^{[18]}$ From Figure 1, we can see that the work locations are mainly distributed in the eastern region while the central and western regions remain relatively small. Especially in the eastern region, Beijing, Shanghai, Guangzhou, and Shenzhen have 81, 46, 23, and 27, respectively, for a total of 177 , which accounts for more than half. In addition, the work location is also concentrated in the provincial capital and the cities in developed provinces,
Table 1: Description of the basic information

\begin{tabular}{|c|c|}
\hline Category & Frequency \\
\hline \multicolumn{2}{|l|}{ Location } \\
\hline Eastern regions & 238 \\
\hline Central regions & 24 \\
\hline Western regions & 14 \\
\hline \multicolumn{2}{|l|}{ Scale } \\
\hline Small & 124 \\
\hline Medium & 125 \\
\hline Large & 27 \\
\hline \multicolumn{2}{|l|}{ Educational background } \\
\hline High school & 1 \\
\hline College & 19 \\
\hline Bachelor's & 221 \\
\hline Master's & 30 \\
\hline Key bachelor or master's & 2 \\
\hline Others & 3 \\
\hline \multicolumn{2}{|l|}{ Number of hirings } \\
\hline Several & 89 \\
\hline Fixed number & 187 \\
\hline \multicolumn{2}{|l|}{ Working experience } \\
\hline Requirement & 169 \\
\hline No requirement & 107 \\
\hline \multicolumn{2}{|l|}{ Major } \\
\hline Not limited to major & 30 \\
\hline Legal or legal related & 6 \\
\hline Science and engineering related & 240 \\
\hline \multicolumn{2}{|l|}{ Certificate } \\
\hline Requirement & 169 \\
\hline No requirement & 107 \\
\hline \multicolumn{2}{|l|}{ Language } \\
\hline Requirement & 153 \\
\hline No requirement & 123 \\
\hline
\end{tabular}

such as Suzhou, Nanjing, Hangzhou, and Xiamen with a total of 40 . The reason for those phenomena should be that patent inventions mainly focus on capital- and technology-intensive industries, so patent agent are primarily concentrated on the spatial distribution of the first-tier cities and eastern coastal areas. In addition, this distribution trend also confirmed that regional economic development has a positive impact on demand for patent agents.

\section{The Scale of the Enterprise}

It is clear that the scale of the enterprise is concentrated in small and medium organizations [Figure 2]. The scale of the enterprise is $<50$ people, $50-150$ people, $150-500$ people accounting for $44.93 \%, 30.43 \%$, and $14.86 \%$, respectively. Compared with the small and medium enterprises, large-scale enterprises, whose scale is more than 500 people, 
account for a total percentage of only $9.78 \%$. The above data show that the current market demands for "patent agent jobs" are mainly small and medium enterprises in China, which also reflect that large-scale enterprises lack innovation power and the demand for patent agents is insufficient.

\section{Analysis of Demand}

From Figure 3, we can see that some enterprises select "several" for the number of recruitments, and the total number is 89 . The reason for this phenomenon is that the demand of enterprises, which according to the change in the actual competency of patent agents and the present status of the company to select patent talents, has flexibility and variability. The recruitment with an uncertain quantity also shows that the demand for "patent agent jobs" in the job market is very active in China. In addition, the number of recruitments in most enterprises is certain, such as 1 person, 2 people to 20 people, 30 people, etc., as determined by the scale of the enterprises. This suggests that those enterprises have a complete organizational structure and detailed division of function, such that they can recruit patent agents according to the position requirements.

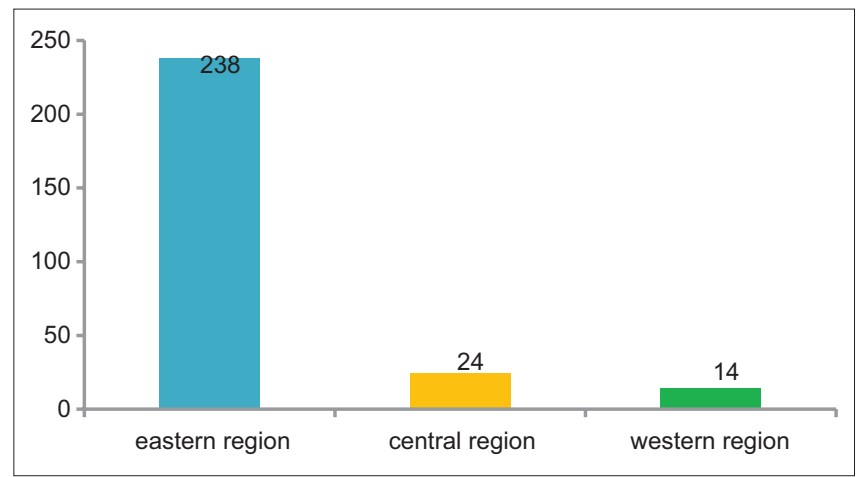

Figure 1: The distribution of patent agencies in China

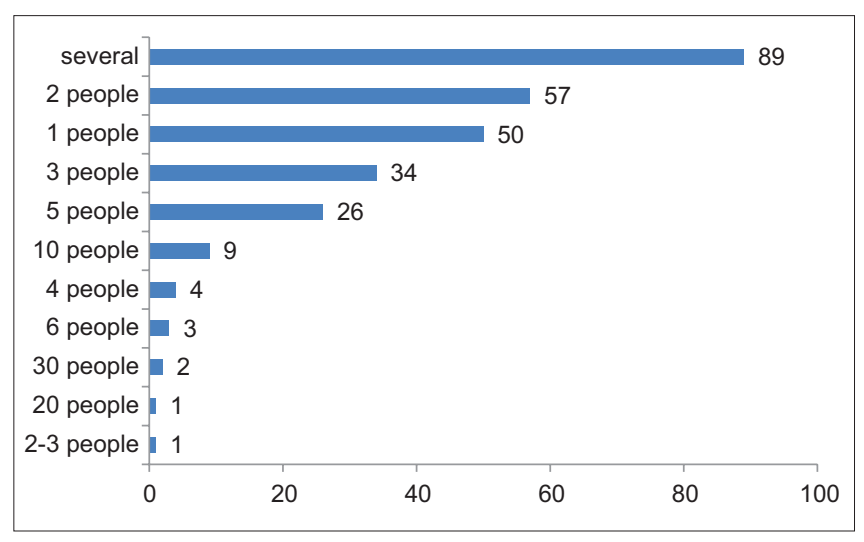

Figure 3: The number of enterprise recruitments

\section{The Quality of Personnel Requirements}

All of the recruitment information was divided into foreign patent agents and domestic patent agents. The number of foreign agents is 13 , and the number of domestic agents is 261 .

\section{Education}

In Figure 4, among the 261 domestic agents information, there are 211 requiring bachelor's degrees, accounting for $80.84 \%$; 19 requiring college and above, accounting for 7.28\%; 26 requiring master's degrees and above, accounting for $9.96 \%$; and 2 having no academic requirements, accounting for $0.77 \%$. In addition, there are 2 requiring a bachelor's degree finished in 985 and 211, funded by both national and local governments to build new research centers, improve facilities, hold international conferences, attract world-renowned faculty and visiting scholars, and help Chinese faculty attend conferences abroad, accounting for $0.77 \%$. While in the 13 foreign agent's information, 8 require bachelor's degrees or above, accounting for $61.54 \%$; 4 require master's degrees and above, accounting for $30.77 \%$; and 1 has no requirement, accounting for $7.69 \%$. The results of the data analysis demonstrate that compared to other occupations, the education demands of enterprises for patent agents is not high, with most being bachelor's degrees, which further illustrate a lack of patent agents in the current Chinese market.

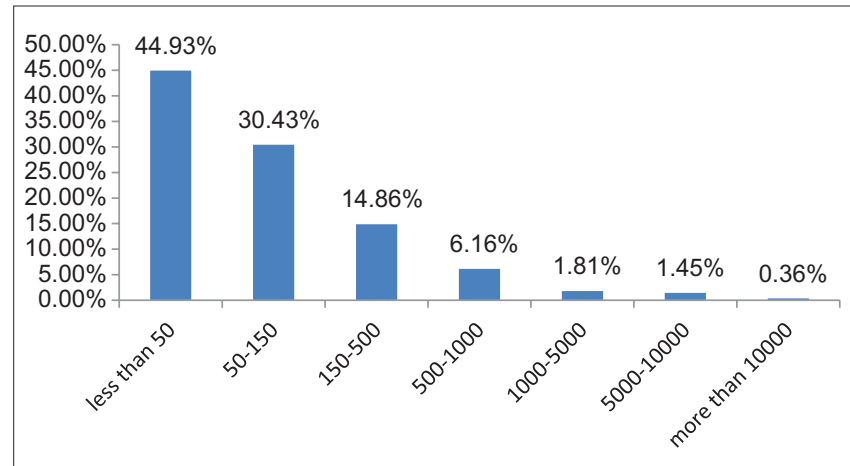

Figure 2: Enterprise scale of demand side

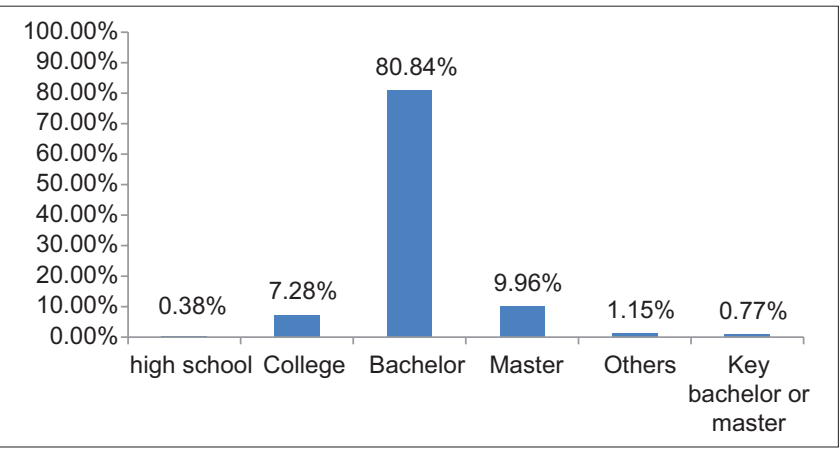

Figure 4: Diploma requirements for patent agents J Scientometric Res. | May-Aug 2015 | Vol 4 | Issue 2 


\section{Major}

Because the major requirements are specific, but can be subdivided and overlap, we divide all of the entries for majors into three categories: Not limited to major, legal or legal-related, and science and engineering related. As is shown in Figure 5, there are 30 of no limited to major, accounting for $10.87 \% ; 6$ are related to the law, accounting for $2.17 \%$; and 240 are of science and engineering, accounting for $86.96 \%$.

Furthermore, we research the different majors of science and engineering because they occupy a large proportion. However, the same majors in different enterprises have different names; this research integrates the diverse major requirements into the following 7 types (taking the major division of Dalian University of Technology as a reference): Electrical and communications, mechanical materials, computer software, chemical industry and environment, biological medicine, automotive engineering, and construction engineering. From Figure 6, we can find that the demand for electrical and communications is greatest, accounting for $80.25 \%$. Following are mechanical materials, computer software, chemical industry and environment and biological medicine. Among them, the proportions of mechanical materials and computer software are also more than $50 \%$, accounting for $65.58 \%$ and $50.81 \%$, respectively. However, the sum demand proportion for automotive engineering and construction engineering is only $8.07 \%$. The results of data analysis suggest that the major requirements for patent agents are closely related to the industry that enterprises are engaged in. However, attention should be paid to some enterprises that do not require a certain major limitation, which can suggest that they require the patent agent to work with flexibility and complexity, thus, those enterprises pay more attention to competency and quality, rather than to the major.

\section{Work experience}

Apart from the strict requirements for majors, enterprises also have high requirements for work experience. As shown in Figure 7, there are 169 enterprises that require work experience, accounting for $61.23 \% ; 107$ do not require work experience, accounting for $38.77 \%$. This finding reflects the importance of experience in patent agent work and the complexity of patent agent's work. However, it reflects the limitation of the patent agency training mechanisms that middle and small enterprises possess.

In those required experience items, working life is also an important influence factor. From Figure 8, we can

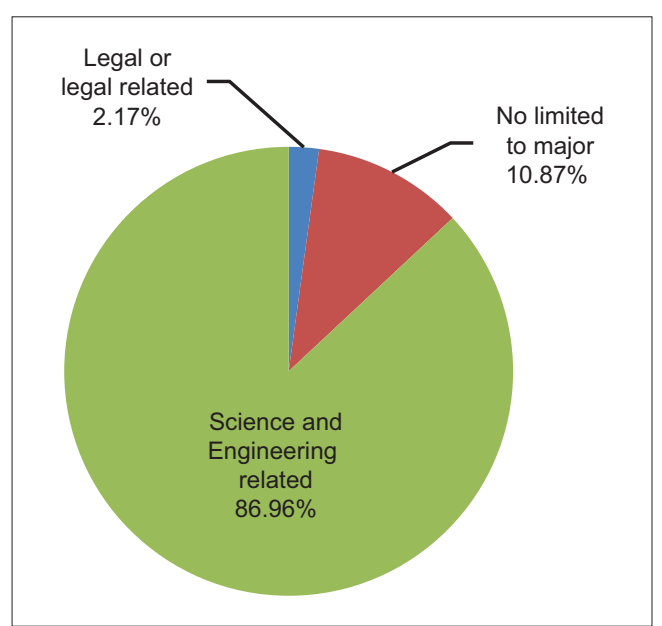

Figure 5: Major requirements for patent agents

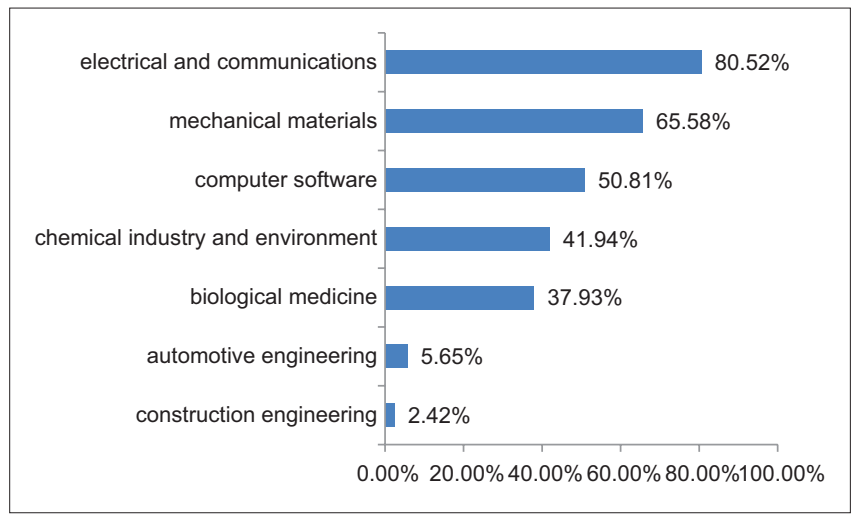

Figure 6: Patent agent specialization

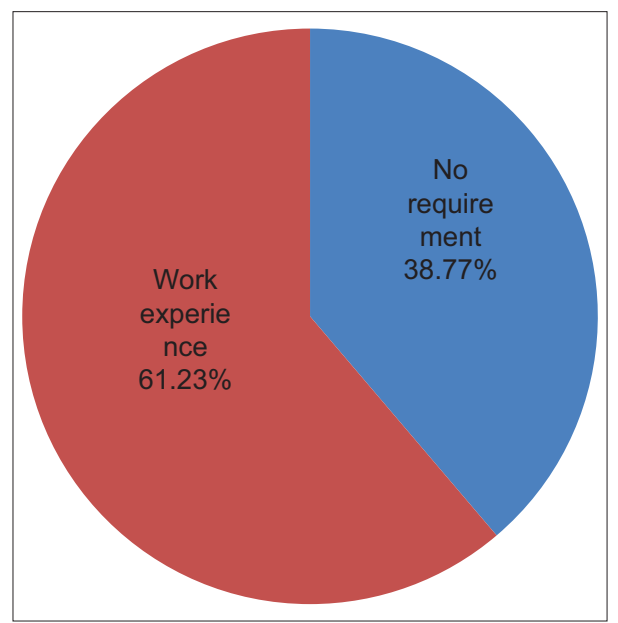

Figure 7: Requirement of work experience

see that those that require 1-year of work experience is $28.99 \%$, those that require 2 years is $20.65 \%$ and those that require 3 years is $11.59 \%$ while those that require 5 years work experience only account for $1.09 \%$. The result demonstrates that enterprise recruits more patent agents with transitory work experience, probably aiming to reduce 
the time of taking over the job. Additionally, 3 years could be a period of transition, leading to a promotion. There are few asking for 5 years or more, meaning the requirements of work experience are not that harsh. Through data analysis, we can see that most enterprises have specific requirements for work experience, but the requirement for working life is not strict. This phenomenon suggests that tacit knowledge (competency), especially wok experience, is important to patent agents. At the same time, it also indicates an active demand for patent agents in China.

\section{Special requirements}

From Figure 9, we can see that there are 50 enterprises requiring patent agent qualification certificates, accounting for $18.12 \%$; only 2 need one to hold the lawyer qualification certificate; 22 ask one to be skilled in CAD or other computer drawing tools, accounting for $7.97 \%$; although the patent agent qualification certificate is not necessary, 133 enterprises state that candidates have priority if they have certificates, accounting for approximately 48.19\%; 9 show give preference to those who can speak a second foreign language; 76 give experience priority, accounting for $27.54 \%$, among which 4 have overseas experience; others such as gender, age and the requirements of computer skills are 5 , which is not representative; 7 prefer higher diploma degrees those beyond undergraduate; 52 enterprises have no special requirements, accounting for $18.84 \%$. For those enterprises that require no work experience (107), there are 68 that have a special requirements for certificates, accounting for $63.55 \%$; 183 prefer the patent agent qualification certificate, accounting for $66.3 \%$. The results of the data analysis demonstrate that the need for patent agents to possess professionalism and special skills plays an important role in improving the service quality and ability of enterprises, so most enterprises provide priority opportunity to recruit patent agent talents; however, patent agents possessing special skills can better meet the demand of patent agent work and have a greater change to being recruited.

\section{The language requirements}

From Figure 10, we can see that there are 153 enterprises that ask for language requirements, accounting for $55.43 \%$, while 123 have no language requirements, accounting for $44.57 \%$. The demand for language accounted for more than $50 \%$, but not the great majority. In the language required entry (153), there are 148 requiring having mastered English, showing that English is a basic quality. In addition to English, there are 25 that ask for Japanese, Korean,

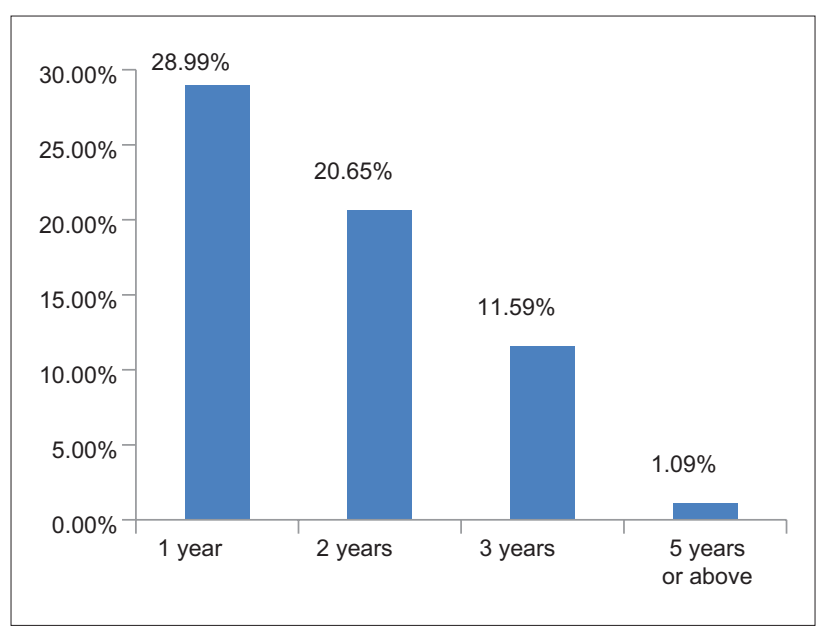

Figure 8: Required years of work experience

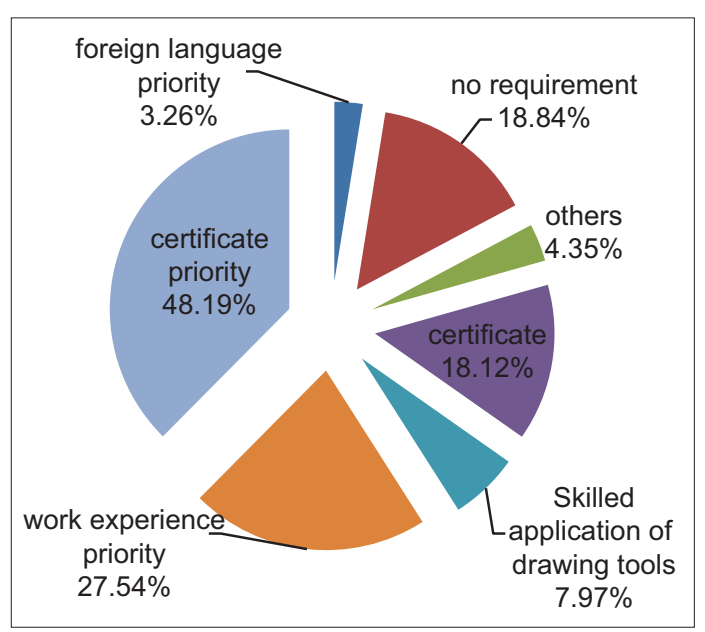

Figure 9: Special requirements of patent agents

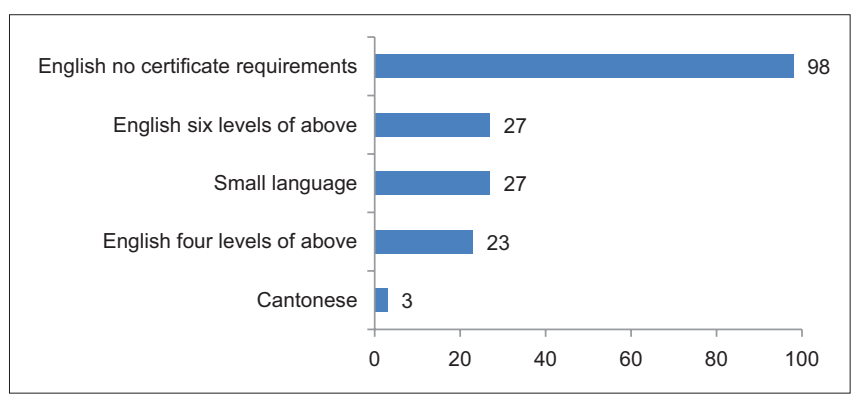

Figure 10: Language subdivision requirements of patent agents

German, French and other languages, being a priority instead of a necessary quality. Those that independently require German, Japanese or Korean are addressing specific national patent agencies, which is similar to the requirement for Cantonese in Guangdong Province. Those entries with English requirements can be divided into CET- 4 or above and CET- 6 or above. There are 23 that ask for CET- 4 or above, 27 ask for CET- 6 or above, and 98 that have no specific certification requirements. Through data analysis, 
we can see that language is a necessary professional skill for patent agents, which can help them in international communication. However, the requirements are not high, further demonstrating that patent agents with excellent language skill are insufficient in China.

\section{CONCLUSION AND DISCUSSION}

Through the comprehensive analysis of various data with the collection of information, we can conclude the following:

- At present, the demand for recruitment of patent agents for social enterprises is great in China, and the patent agency and intellectual property industry demand will continue to expand, which is a good development trend. However, the quantity of agents cannot meet the social needs, and the degree requirements for patent agents are not very high but emphasize work experience. The requirements from enterprises for a patent agent gradually focus on the mastery of the patent agency process or relevant patent agency experience. Therefore, the lower degree requirements and higher experience requirements make the diploma not a restriction for the application. This leads to a patent agent only attaching great importance to work experience, and ignoring the importance of patent knowledge and skills, which will cause a serious negative impact on the development of the patent in China

- The distribution of patent agents is extremely uneven in China. Patent agents have technical-intensive jobs, so the enterprises are mostly distributed in the economically developed eastern coastal areas and first tier cities, while the central and western cities with poor economic conditions virtually have no demand. This phenomenon can promote the patent to develop rapidly, but to some extent, it also restricts the common development of patents, leading to the frequent turnover of talent and the innovation of enterprises, dashing the stability of the patent in China. In addition, the postdemand is concentrated in small and medium enterprises, showing that the future development of enterprises has great space and diversification

- The professional direction of patent agents is very clear and specific, and has many limits in terms of science and engineering but is more wider in the coverage of science and technology, showing the complicity and pertinence of patent agents, which can provide a large number of professional agents to meet the social needs. However, the teaching mode of technology universities has some problems. They are heavy and monotonous so that the possibility of finding the platform of students is not large, and there is a big gap between the training mode and talent demand. To a certain extent, it restricts the improvement of the professional agent's comprehensive quality. In addition, some enterprises do not set a "limit to majors," which reflects the comprehensiveness and flexibility of their work and unpredictable changes in the future

- Patent agent qualification certificates are not necessary in the recruitment, which further indicates that the patent agent qualification certificate examination is difficult and that there is a gap between the patent agent examination and the actual demand from enterprises. However, the perception of English language requirements is high, demonstrating that specification language elements for patent agent quality are very important. The enterprises ask for high language levels and prefer one to possess skills in a second foreign language. In fact, the heavy academic workload caused a language deficiency for the most undergraduate students that were very high for science and engineering students, in particular. In addition, some enterprises have English certificate request, matching the requirements, including CET-4/CET-6 for undergraduates, which is worthy of further promoting and enhancing.

However, according to current demand for professional agents in our country and the conclusion of normative investigation and data analysis, this research also puts forward some countermeasures.

1. Universities of science and engineering could provide more opportunity for students to practice in setting up courses, use summer and winter vacations, provide students with case studies on patent agency and practice in enterprises to enhance students' experience of the position while in university

2. The limitation of relevant patent agent qualification exams should be improved, and the exam should be closely related to the actual needs of enterprises. In addition, enterprises should increase the role of the patent agent qualification certificates in recruitment

3. The government should strengthen policy support to the central and western regions intellectual property agencies so that they provide relatively stable and professional training channels for the patent agency services. At the same time, the central and western regions polytechnic universities should be encouraged to establish intellectual property talent "master's" or "doctoral" diplomas and cultivate more professional agents 
4. Mainstream media public opinion should be strengthened. The relative agency should film popular science documentaries concerning intellectual property and play them in the mass media. In addition, the agency should explore the cover of patent agent through the introduction of patent agent qualification exams and establish a relevant positive public brand for patent agencies to increase the influence of positive externality.

\section{LIMITATIONS AND PROSPECT}

The recruitment information employed by this research is derived from a well-known recruitment website in China. All data are updated in a timely manner, which not only provides the latest data source for the research, but also ensures that the data are objective and authentic to explain the needed quality from the market for a patent agent and provides reliable and detailed information for the construction of patent agent quality configuration.

However, the screening process for a large number of records and nodes selected is a difficult point of this research. Therefore, the research has some limitations. There is a partial and inevitable preference of data selection and entry errors due to the huge information and limited researchers. At the same time, by choosing February to April as the period for collecting related data, there may be some bias. In addition, there are certain differences between the network recruitment and the real enterprises' requirements that may lead to some partial distortion of the information. In the following research, we will employ a questionnaire to conduct further verification to obtain more precise and scientific analysis results. Based on those analysis data, we can conduct correlation analysis and regression analysis of the related factors with SPSS 18.0 software to explore the special relationship among the factors which influence patent agent quality, such as positive correlation or negative correlation and construct an accurate and valid model and combine the difference between the contrast of patent agent quality and students' quality to put forward some suggestions.

\section{ACKNOWLEDGMENTS}

This work was supported by the project "Specialized Research Fund for the Doctoral Program of Higher Education - Research on Quality Configuration and Influence Mechanism of Patent Agents: Based on the Competency Model" (20130041120049), the project "Fundamental Research Funds for the Central Universities" (DUT13RW409) and the project "the Soft Science Research Project of State Intellectual Property Office - Study on Competency and Promotion Polices of Patent Attorneys from the Angle of Patent Application Quality."

\section{REFERENCES}

1. Ma ZZ, Lee Y, Chen CF. Booming or emerging? China's technological capability and international collaboration in patent activities. Technol Forecast Soc Change 2009;6:787-96.

2. $\mathrm{Qu} Z$, Shen $X \mathrm{~L}$, Ding K. Comparative analysis on technologies between Chinese and American large-sized oil companies based on patentometrics. J Scientometric Res 2014;3:68-74.

3. Malti G, Vandana M, Pranav ND. R and D indicators and mapping of solar energy research output in India. J Scientometric Res 2013;2:52-8.

4. Tulasi GK, Rao BS. A detailed study of patent system for protection of inventions. Indian J Pharm Sci 2008;70:547-54.

5. Sylva H, Mol ST. E-recruitment: A study into applicant perceptions of an online application system. Int J Sel Assess 2009;17:311-23.

6. Patent Attorney. Webpage. Wikipedia, the Free Encyclopedia. Available from: http://www.en.wikipedia.org/wiki/Patent attorney. [Last accessed on 2015 Jan 18].

7. Cropp JA. An industrial patent agent looks at his work. Aslib Proc 1968;20:378-86.

8. Lamoreaux NR, Sokoloff KL, Sutthiphisal D. Patent alchemy: The market for technology in U.S. history. Bus Hist Rev 2013;87:3-38.

9. Yun SH. A study on Japanese patent attorney act in assistance of amending the Korean patent attorney act. J Ind Prop 2013;40:313-76.

10. Bottomley S. The British Patent System During the Industrial Revolution, 1700-1852. Colombia: University Cambridge Press; 2014. p. 47-50, 180.

11. Liu YW, Xu N, Zhang WJ. The key role of patent agent. J Univ Sci Technol Beijing (Soc Sci Ed) 2006;22:94-7.

12. Macdonald S, Lefang B. Measuring innovation: The patent attorney as an indicator of innovation. Comput Law Secur Rep 1998;14:8-13.

13. Thacker D. The role of the patent agent. Eng Manag J 2004;14:24-5.

14. Ralph DC, Thomas GF, Jon RC. A statistical analysis of the patent bar: Where are the software-savvy patent attorneys? N C J Law Technol 2010;11:223-68.

15. Gaff BM. IP issues for start-ups. Browse J Mag 2015;48:16-8.

16. Kaushik M. Time to be a patent agent. Bus Today 2011;20:139-9, 0-74.

17. Walker C. Patent law: Finding a balance. Nature 2014;511:621-3.

18. Sun YF. Spatial distribution of patents in China. Reg Stud 2000;34:441-54.

How to cite this article: Gu L, Zhou Y, Ren L, Yan W. Analysis of occupational demand for patent agents in China - Based on the network data of recruitment. J Sci Res 2015;4:77-84.

Source of Support: Nil, Conflict of Interest: None declared 